\title{
The translation of animal welfare research into practice: The case of mixing aggression between pigs
}

\author{
Rachel S.E. Peden ${ }^{\mathrm{a}, \mathrm{b}, *}$, Simon P. Turner ${ }^{\mathrm{a}}$, Laura A. Boyle ${ }^{\mathrm{c}}$, Irene Camerlink ${ }^{\mathrm{a}}$ \\ a Animal Behaviour \& Welfare, Animal and Veterinary Sciences Research Group, Scotland's Rural College (SRUC), West Mains Rd., Edinburgh, EH9 3JG, United Kingdom \\ ${ }^{\mathrm{b}}$ The Roslin Institute and Royal (Dick) School of Veterinary Studies, University of Edinburgh, Easter Bush Campus, Midlothian, EH25 9RG, United Kingdom \\ c Teagasc, Pig Development Department, Animal \& Grassland Research and Innovation Centre, Moorepark, Fermoy Co. Cork. P61 C997, Ireland
}

\section{A R T I C L E I N F O}

\section{Keywords:}

Pig

Sow

Aggression

Industry

Farmers

Animal welfare

\begin{abstract}
A B S T R A C T
Aggression between unfamiliar pigs at mixing is a major animal welfare problem in commercial farming. It has been studied since the 1970s and remains an important topic in animal welfare research. Methods to reduce pig aggression at mixing have been reviewed previously, but there has been little translation of the advocated techniques and building designs into practice. As a result, the problem persists on many commercial units. A similar situation exists for many other animal welfare issues. This article takes a new approach in not only reviewing the recent scientific literature, but also reviewing the evidence of uptake in industry. Firstly, the current state of aggression mitigation research is reviewed; including the most successful recent developments in breeding against aggression, early life socialisation, the use of pheromones and nutrition. Secondly, information is extracted from both peer reviewed and industry literature to establish the extent to which these strategies have been transferred from research to practice. Finally, we discuss why in spite of the amount of research on reducing aggression at mixing the problem has not reduced in intensive farming systems. The limited uptake in practice appears to be due to low prioritisation of the problem, the practicalities of implementation, lack of information on cost-effectiveness and ineffective communication of research to the farming community. To bridge this gap, industry must be involved in the design of practical solutions and the cost-effectiveness of these must be quantified. This approach should also be considered for other animal welfare issues under investigation. We recommend a better alignment between research questions and industry interests to increase the success of research efforts to improve animal welfare in practice.
\end{abstract}

\section{Introduction}

When regrouping ('mixing') unfamiliar pigs, aggression occurs as they establish a dominance hierarchy. 'Mixing aggression' between both growing pigs and sows is a major animal welfare issue. It has been studied since the 1970s and a large body of peer-reviewed literature exists. Many strategies to reduce aggression have been identified. Methods for growing pigs and sows were reviewed by Marchant-Forde and Marchant-Forde (2005), whilst other reviews focussed specifically on growing pigs (Petherick and Blackshaw, 1987) or sows (Arey and Edwards, 1998; Greenwood et al., 2014). Despite the amount of past and on-going research, aggression at mixing is largely undiminished in practice, which is partly evidenced by the on-going research efforts on this topic. Projects on aggression in pigs continue to receive funding as it is still regarded an important welfare issue. In fact, research on pig aggression has increased since the reviews cited above (Fig. 1). Data from 1,928 farms in the UK show a prevalence of $0.24 \%$ for severe skin lesions (Pandolfi et al., 2017) and 11\% for mild body lesions (Real Welfare, 2017), which are a result of aggression.

Aggression between pigs arises from their need to establish and reinforce dominance relationships (McGlone, 1985). Although aggression is a natural behaviour, it is exacerbated by unnatural intensive farming conditions and practices such as social disruption, limited space and homogeneity in competitive ability of group members. In the wild, pigs live in small stable groups where subordinate animals tend to actively avoid conflict with dominant animals (Jensen and Wood-Gush, 1984), and males actively avoid confrontation with each other outside of the mating season (Gabor et al., 1999). Social hierarchies are therefore maintained mostly through agonistic display and with little physical aggression. In commercial pig production pigs are regrouped several times from birth to slaughter (Camerlink and Turner, 2017). Regrouping is a common management strategy 1) to create groups

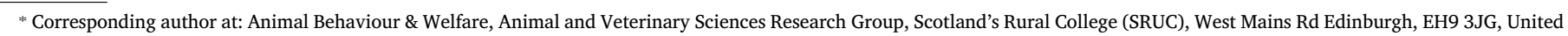
Kingdom.

E-mail address: Rachel.peden@sruc.ac.uk (R.S.E. Peden). 


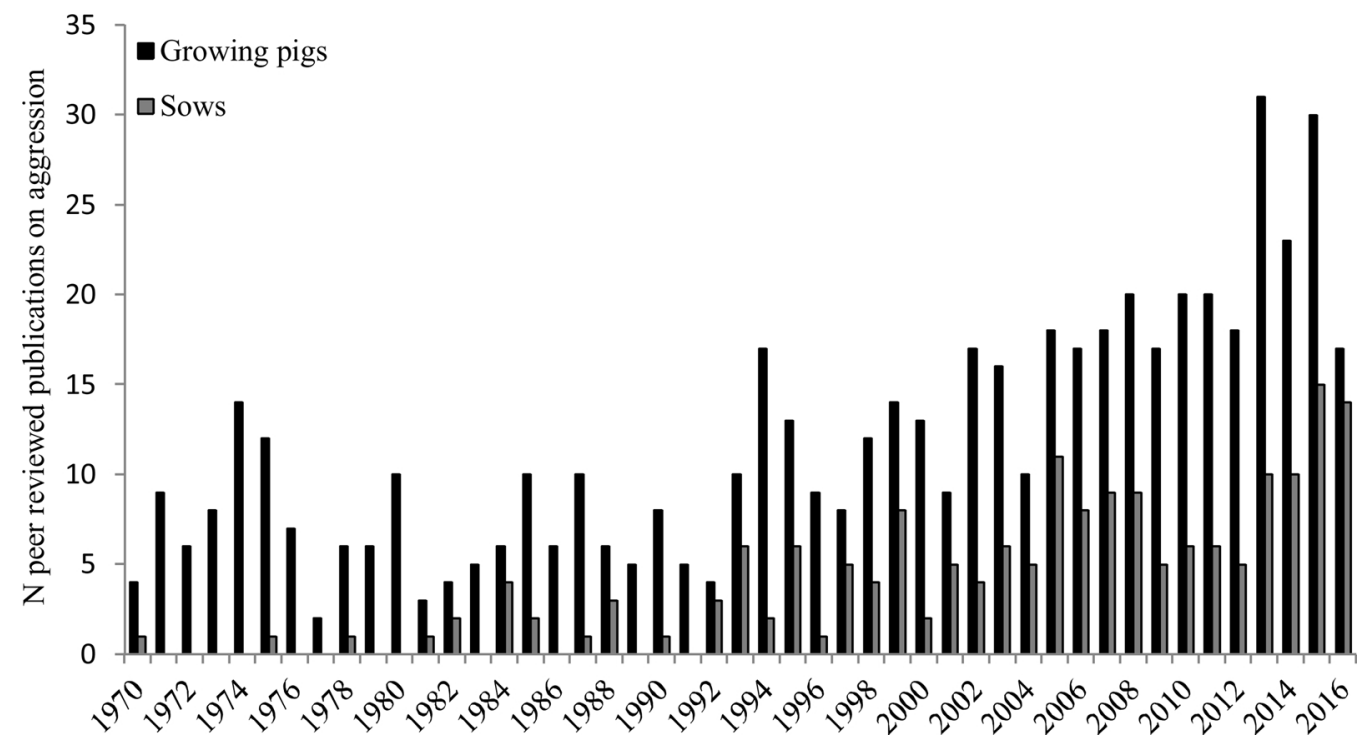

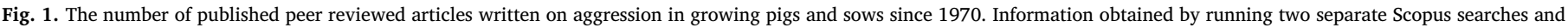
noting the number of hits per year (searched 'aggression AND pigs' and 'aggression AND sows').

appropriate to the size of the pens available (Guy et al., 2009); 2) to equalise body weights to achieve more homogenous slaughter weights (Rushen, 1987); and 3) to return breeding sows to the gestation group after weaning. Farmers report mixing growing pigs up to four times during production (Camerlink and Turner, 2017). For the majority of farmers, the avoidance of mixing is impractical due to inefficient use of space and concern that heterogeneity in pig weights will be exacerbated. Moreover, the mixing of sows is unavoidable in the EU due to EU Council Directive 2008/120/EC which requires that sows and gilts are group housed from 4 weeks after service to 1 week before expected farrowing. Regrouping, and thus aggression, is therefore common at weaning (for both piglets and sows), at the beginning of the growing-finishing period (Manteca and Jones, 2013) and at transport to slaughter (Terlouw et al., 2008).

Aggression has a negative impact on farm profit and animal welfare. During fights pigs acquire skin injuries as a result of bites (McGlone, 1985), risk lameness (Rydhmer et al., 2006), and are more susceptible to infection due to the transient effects of stress upon the immune system (Morrow-Tesch et al., 1994). Aggression can negatively affect growth rate (Stookey and Gonyou, 1994; Coutellier et al., 2007) and meat quality (D'Eath et al., 2010). In sows, aggression can result in economic losses due to reduced reproductive performance (Mendl et al., 1992; Greenwood et al., 2014). The movement away from individual sow stalls, which is now taking place globally, means research into aggression when re-grouping sows is of increasing importance (e.g. Greenwood et al., 2014; Ison et al., in press).

In this paper we review the current state of research into reducing mixing aggression between growing pigs and sows, and identify the most promising techniques in terms of their scientific progress. Moreover, we review the impact of these strategies on commercial practice, and address why the large amount of research on this topic has failed to reduce aggression on commercial pig farms. Finally, we provide suggestions on how to bridge the gap between animal welfare research and actual animal welfare improvement. We focus specifically on the aggression that occurs between unfamiliar pigs at regrouping. Strategies to address problems of aggression between pigs in stable groups are not explored in this review.

\section{Method of selecting literature}

The review of aggression mitigation strategies for both sows and growing pigs carried out by Marchant-Forde and Marchant-Forde
(2005) was used in this review to refer to the scientific literature up to 2005. Peer-reviewed literature published between 2005 and 2017 was identified using Google Scholar and Web of Science using the following search terms: Pig, Sow and Aggression. The uptake of methods to reduce aggression in practice was assessed through data from farmer surveys and a Web based search of commercial publications, websites, and farmers' magazines. Findings from farmer surveys were identified using Google Scholar and Web of Science under the following search terms: Pig, Sow, Aggression and Survey. Websites included those of pig farming magazines, pig breeding companies, pig feed companies and equipment manufacturers or suppliers based in the United Kingdom. Information obtained from websites included items promoting specific aggression mitigation strategies and the availability of relevant products on the market. Social media, blogs, and posts by lay people were excluded. Literature on aggression between pigs in stable groups was also excluded.

\section{Current state of research}

In this section we summarise the successful methods to reduce aggression identified in previous reviews. Thereafter, four newer approaches are described, namely: genetic selection, nutritional supplementation, early-life socialisation and use of pheromones. In recent years these four approaches have emerged as some of the most promising aggression mitigation strategies in terms of their scientific progress and practical impact.

\subsection{Previously identified control strategies}

Research has moved away from methods that do not deliver long term benefits and prove difficult to manage under commercial conditions, such as tranquilisers, boar presence and variation in weight at mixing (described by Marchant-Forde and Marchant-Forde, 2005). Methods with continued efficacy in empirical studies include providing adequate space (Spoolder et al., 2009; Hemsworth et al., 2013) and large social groups (Samarakone and Gonyou, 2009). Space allowance should be sufficient for pigs to display submissive behaviour (Turner et al., 2000; Spoolder et al., 2009; Hemsworth et al., 2013); however, to date it is difficult to define what can be regarded as adequate space allowances for growing pigs and sows, partly since this is affected by floor type and feeding system design. Group size must be sufficiently large (more than 12 individuals) to have an impact on aggression levels 
(Andersen et al., 2004), however much larger groups ( $>80$ pigs) are more effective (Turner et al., 2001; Samarakone and Gonyou, 2009). It is suggested that the reduction in aggression with increasing group size is related to the formation of subgroups of a more natural size when pigs can no longer maintain a definitive social order (Gonyou, 2001). However, there is no clear evidence for this in domestic pigs (Turner et al., 2003), and it more likely reflects the adoption of a less aggressive social strategy when the costs associated with aggression outweigh the benefits (Andersen et al., 2004; Samarakone and Gonyou, 2009).

\subsection{Advances in genetics}

Aggressiveness is a moderately stable temperament trait with consistent differences existing between individuals. For example, resident pigs exposed to intruders at three time points (60, 95 and 130 days old) revealed consistency in their aggressive behaviour within and between interactions (Clark and D'Eath, 2013). The distribution of aggressive behaviour within a group tends to be skewed by the presence of a minority of highly aggressive animals (Turner et al., 2006b). The aim of breeding against aggression would be to reduce the aggressiveness of all animals in the population with greatest impact on the occurrence of highly aggressive individuals. Reciprocated fighting and the delivery of non-reciprocated bullying have a moderate heritability $\left(\mathrm{h}^{2}=0.17-0.43\right.$ ) (Lovendahl et al., 2005; Turner et al., 2008, 2009) whereby the heritability indicates the proportion of the phenotypic variance that can be attributed to additive genetic effects. Reciprocated fighting involves decisions made by two pigs and the significant heritability estimated for this behaviour reflects an individual's propensity either to initiate aggression or to retaliate aggressively when attacked, leading to a reciprocal fight. However, the heritability for the receipt of bullying is low $\left(\mathrm{h}^{2}=0.04-0.08\right.$; Lovendahl et al., 2005; Turner et al., 2009). Skin lesions are used as a proxy measure of aggression, with a differentiation being made between skin lesions due to reciprocal fighting (primarily located on the head, neck and shoulders) and lesions due to the receipt of bullying (primarily located on the flanks, back and rump) (Turner et al., 2006a; Desire et al., 2015b). Skin lesions, particularly towards the front of the body, are genetically correlated with engagement in reciprocal fighting and pigs which perform this behaviour typically also direct non-reciprocated bullying towards others (Turner et al., 2009). Therefore the amount of lesions and their location on individual pigs can be used as a genetic indicator trait to select against the expression of reciprocal fighting and aggressive behaviour (Turner et al., 2006b, 2008, 2010; D'Eath et al., 2010; Desire et al., 2015a,b).

Counting lesions takes less than 2 min per animal (Turner et al., 2009) and requires no additional animal handling, no equipment and minimal training (Turner et al., 2010). Therefore genetic selection on the basis of skin lesions has the potential to lead to cumulative and long term benefits at relatively little cost to individual producers. However, the costs of recording lesions (phenotyping) and the reduction in selection pressure that can be exerted on other traits in an index by the inclusion of a new trait are barriers to selection against skin lesions. Furthermore, there is evidence from one population that reducing skin lesions may slow genetic progress in growth rate and feed efficiency (Desire et al., 2015a) due to an undesirable genetic association between the traits. Nevertheless, it is important to note that lesions are primarily received to the anterior part of the body during aggressive behaviour and these are not genetically related to production traits (Desire et al., 2015a).

A novel approach to address animal welfare issues through breeding is through indirect genetic effects (IGEs, also known as social or associative genetic effects). An individual's performance is influenced not only by its own genotype, but also by that of the individuals with which it interacts (Moore et al., 1997; Ellen et al., 2014). IGEs refer to the genetic effects that an individual has on the phenotype of its group mates. These effects can have either positive or negative implications for welfare, productivity, and health of livestock and are hypothesised to be related to behaviour (reviewed in Ellen et al., 2014). Indeed, research on the behaviour of pigs selected for positive IGEs regarding productivity showed differences in biting behaviour (Canario et al., 2012; Camerlink et al., 2013). IGEs may, therefore, provide a promising method for reducing negative social interactions whilst improving productivity. This approach negates the need for additional phenotyping as it is expected to change social behaviour as an indirect consequence of improving productivity traits that are already recorded.

\subsection{Nutrition}

Scientific research on how nutrition can reduce aggression is sparse but promising. There is some evidence to suggest that magnesium supplementation may reduce aggressive behaviour at mixing (O'Driscoll et al., 2013a, b), although there is also evidence to suggest that it can actually increase the frequency of aggressive behaviour (Caine et al., 2000). Therefore further research is required to establish the effect of magnesium on aggression and the optimum supplementation level.

Dietary manipulation of amino acid precursors of neurotransmitters may offer a practical means of reducing susceptibility of pigs to stress (Adeola and Ball, 1992; Koopmans et al., 2005). Tryptophan (TRP) is an essential amino acid acquired through the diet, and is typically supplied at levels required for maximum growth (Li et al., 2006). The supply of excess TRP may be used as a therapeutic supplement as it is the primary precursor for serotonin (5-HT), an inhibitory neurotransmitter in the central nervous system (Li et al., 2006). Serotonin regulates a variety of processes such as sleep, appetite, mood, susceptibility to stress and aggressive behaviour (D'Eath et al., 2005; Koopmans et al., 2005; Poletto et al., 2010). By feeding pigs a high TRP diet it is possible to indirectly raise brain availability of 5-HT (Adeola and Ball, 1992; Koopmans et al., 2006; Shen et al., 2012a). A four day enhanced TRP diet was associated with a 50\% decrease in fight duration and intensity at regrouping in male and female growing/finishing pigs compared to an untreated control group (Li et al., 2006). There was no effect of an enhanced TRP diet on the number of fights that occurred or the latency to fight (Li et al., 2006). Poletto et al. (2010) found that a high TRP diet significantly reduced the aggressiveness of grower gilts in a resident intruder test as they took longer to attack the intruder pig and they initiated fewer fights (Poletto et al., 2010). Moreover, providing a TRPenriched diet around mixing led to a reduction in aggressive behaviour in gestating sows (Poletto et al., 2014), although Li and co-authors (2011) did not find such an effect (Li et al., 2011). Hypothalamic 5-HT concentrations peak after 4-5 days of eating an enhanced TRP diet (Adeola and Ball, 1992; Koopmans et al., 2005), and this was missed in the study of Li et al. (2011).

A TRP-enriched diet is also associated with reduced salivary cortisol (Koopmans et al., 2005; Guzik et al., 2006; Koopmans et al., 2006; Shen et al., 2012a) and reduced adrenaline and noradrenaline at regrouping (Koopmans et al., 2005). Moreover, growing pigs with a TRP-enriched diet display a reduced long term hormonal response to regrouping, indicating enhanced recovery following social confrontations (Koopmans et al., 2005). When weaned pigs are placed on a TRP-enriched diet immediately following weaning, no adverse effects on feed intake and average daily gain are reported (Koopmans et al., 2006) and there can be improvements in feed efficiency (Shen et al., 2012b). However, there is no reduction in aggressive behaviour when mixed five days after weaning (Koopmans et al., 2006).

\subsection{Early life socialisation}

Early life socialisation of piglets, also termed co-mingling, involves the mixing of litters during the lactation period and is probably the most studied method for mitigating aggression at weaning. Suckling litters are allowed to integrate usually in the second week of life, when piglets would start to encounter other litters under natural conditions 
(Stolba and Wood-Gush, 1989), and remain together until weaning. Unless using purpose-built multi-suckling systems, in which piglets naturally co-mingle, socialisation requires the removal of the barriers between adjacent farrowing pens (Hessel et al., 2006).

There is little increase in agonistic behaviour in piglets at preweaning socialisation (Weary et al., 1999), and when aggression does occur it is without the risk of severe injuries due to the limited size and strength of young piglets (Ledergerber et al., 2015). This social experience results in reduced aggression at weaning, and is presumed to do so by allowing piglets to learn social skills which permit more rapid formation of stable dominance relationships in subsequent social encounters (D'Eath, 2005; Kanaan et al., 2008; Kutzer et al., 2009). Moreover, pre-weaning socialisation can improve weaner performance by increasing growth rate following weaning (Hessel et al., 2006; Ledergerber et al., 2015).

There is some concern that the benefits of socialisation may be offset by production costs resulting from a disruption to pre-weaning feeding behaviour (Wattanakul et al., 1997b; Parratt et al., 2006). The main concern regards cross-suckling, which can lead to reduced milk intake due to competitive exclusion of subordinate piglets (Pedersen et al., 1998) and a disruption to sow lactation at mixing (D'Eath, 2005). There is inconsistent evidence regarding the prevalence of cross-suckling in multi-suckling systems; some studies found that it occurred frequently (Wattanakul et al., 1997a; Olsen et al., 1998; Maletinska and Špinka, 2001) whilst others did not (D'Eath, 2005; Kutzer et al., 2009). Moreover, there is evidence to suggest that even where cross-suckling is common it does not have an adverse effect on the overall milk intake of the piglets (Maletinska and Špinka, 2001). Experimental studies suggest that pre-weaning socialisation of pairs of litters does not affect preweaning growth rate (D'Eath, 2005; Kanaan et al., 2008) or mortality (D'Eath, 2005). However, heightened mortality was observed in multisuckling systems where more than two litters were simultaneously comingled (van Nieuwamerongen et al., 2015).

\subsection{Pheromones}

Pig appeasing pheromone (PAP) is a maternal pheromone released by sows through skin secretions, and functions to regulate nursing behaviours (Morrow-Tesch and McGlone, 1990). Pageat (Pageat, 2001) synthesised a mixture containing several fatty acids similar in composition to PAP and it is currently on the market as an odour diffuser to reduce pig aggression. This synthetic pheromone reduces the frequency of fights at mixing in sows (Yonezawa et al., 2009; Plush et al., 2016) and weaners under experimental (McGlone and Anderson, 2002) and commercial farming conditions (Guy et al., 2009). This technique is therefore targeted at breeding and weaner stock. Research applying synthetic PAP in either aerosol or liquid form directly to pens and feeders found that pigs showed a reduction in salivary cortisol (Yonezawa et al., 2009) and skin lesions related to aggression (Guy et al., 2009) and a higher average daily weight gain (McGlone and Anderson, 2002) when compared to pigs not exposed to PAP. The use of synthetic PAP for sows does not appear to affect the subsequent conception rate (Plush et al., 2016). The number of skin lesions in groups exposed to synthetic PAP is reduced up to seven days following mixing (Guy et al., 2009), suggesting that it does not merely postpone the occurrence of aggression but results in the more rapid formation of stable social relationships (Guy et al., 2009).

\section{Implementation of aggression mitigation methods in practice}

We summarise the translation of aggression research into commercial practice in Table 1. All aggression mitigation methods were tabulated, even those that research found ineffective but industry found useful in the study of Ison et al. (in press). Methods were grouped by breeding strategy, nutrition, and management adaptations. In the rest of this section, we summarise the evidence for implementation of the most promising control strategies. Firstly, we summarise uptake of the most promising previously identified strategies (increased space allowance and group size) before summarising uptake of the most promising recent developments in aggression research (genetic selection, nutritional supplementation, early life socialisation and use of appeasing pheromones).

\subsection{Previously identified control strategies}

A recent survey found that only two respondents from a sample of 132 British and Irish pig farmers reported using increased space allowance to control aggression at mixing (Peden et al., Unpublished work) suggesting limited uptake of this strategy in practice. Keeping pigs in large groups of anything from 50 to 1000 pigs gained popularity over the last 15 years (Gadd, 2009) due to a reduction in aggressive behaviour (Turner et al., 2001; Samarakone and Gonyou, 2009), and benefits in terms of reduced cost and ease of management (Gadd, 2009). The growth in group size for growing pigs has been accelerated by the development and launch of Automatic Sorting Technology (AST) in 2002, which is based on maintaining pigs in groups of 500-1000 (Brummer et al., 2008).

\subsection{Breeding}

Although direct genetic selection against aggression shows promise and continues to be researched it is not being implemented in pig breeding schemes. The finding that lesions to the anterior part of the body (which are most associated with aggressive behaviour) are not genetically related to production traits (Desire et al., 2015a) is promising for future implementation. As the costs of high density genotyping (i.e. determination of the nucleotide identity at many locations on the genome) fall, genomic selection based on lesions is likely to become more feasible and will avoid the need for routine phenotyping. The estimation of indirect genetic effects, which could also affect aggression, is routinely conducted by two large pig breeding companies and is being evaluated by others. To date, only a limited number of lines selected for indirect genetic effects are commercially available from two companies.

\subsection{Nutrition}

Several articles have appeared in popular farmer magazines and websites that promote the use of an enhanced tryptophan diet to reduce aggression (Dapoza, 2009; Ziggers, 2009; National Hog Farmer, 2010; Phys.Org, 2010; Salvage, 2010; ter Beek, 2010; Ziggers, 2010). Despite these, tryptophan is not commonly used above the minimum requirements for growth in commercial practice. Tryptophan is not readily available for supplementing feed, nor is its supplementation routinely recommended by feed companies. This is likely related to the inconsistent dose response reported in the literature, and lack of information on the economic benefits. In order to bring enhanced TRP out of the research phase and into practical application we recommend that research establishes the optimum dose and the associated cost to farmers. Moreover, it is important to establish a way of administering an enhanced TRP diet for the necessary period with minimal disruption to management.

\subsection{Early life socialisation}

A recent survey amongst UK pig farmers indicated that $27 \%$ of the 167 respondents currently applied socialisation of piglets, or had done so in the past (Camerlink and Turner, 2017). However, 50\% of participants said they would not employ socialisation, and most raised multiple concerns about the strategy. The most frequently mentioned concern regarded the practical management of piglets and sows $(60 \%)$, followed by aggression of the sow towards piglets (37\%) and reduced 


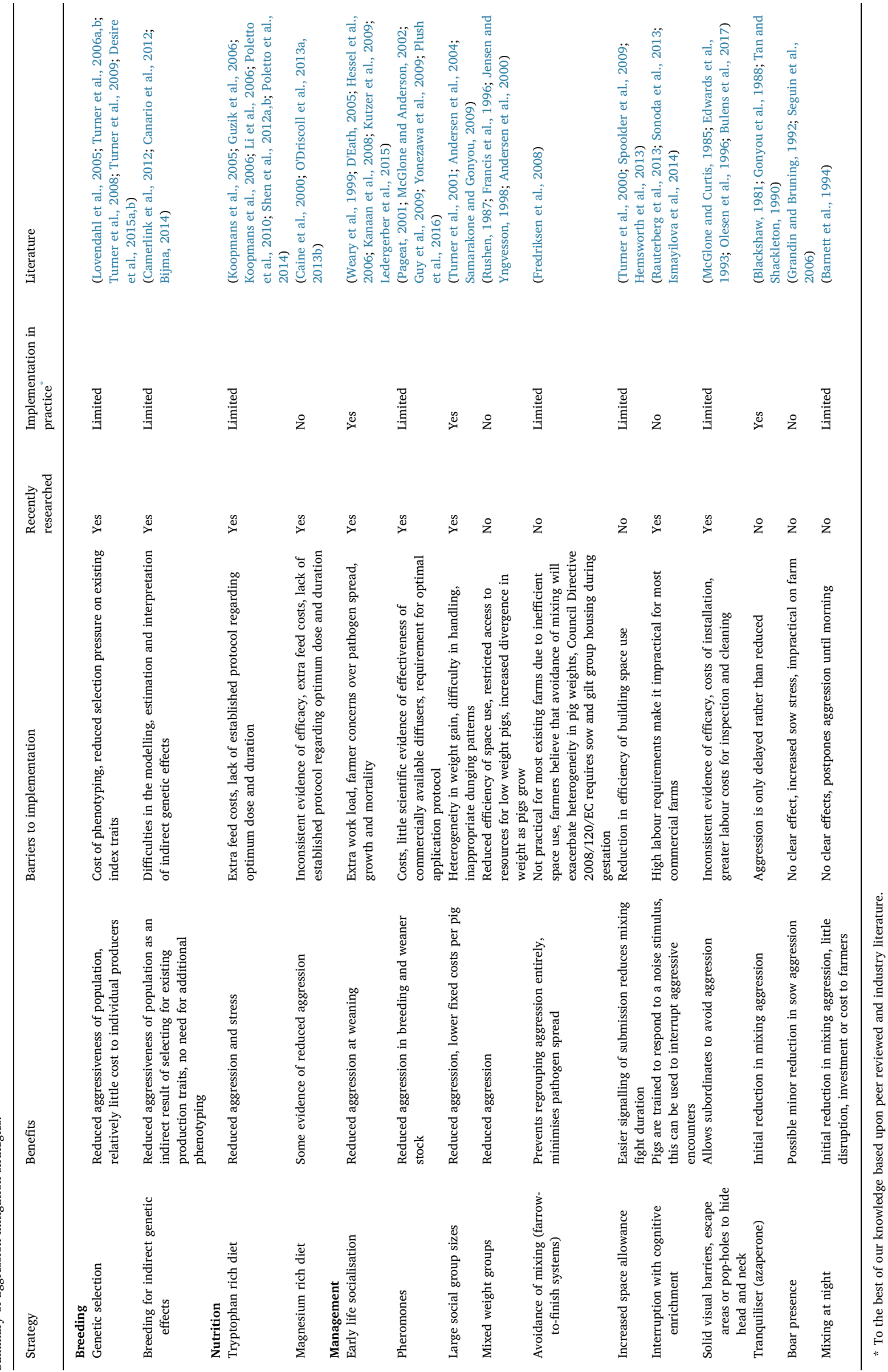


growth of piglets (32\%). These concerns are not supported by experimental trials but results in practice may differ from those generated under highly controlled experimental conditions. Producers may be more willing to implement early-life socialisation if more evidence is provided and disseminated to demonstrate that growth and mortality are comparable to standard practice (Ison et al, in press).

Implementation of this technique outside of the UK is currently unknown. Unusually, as much as $40 \%$ of the British pig herd is outdoor bred (Agriculture and Horticulture Development Board, 2016), and early life socialisation frequently occurs as a consequence of these outdoor rearing systems. Therefore implementation reported in the UK is likely to be relatively high in comparison to countries where indoor intensive breeding systems are more common. Indeed, a recent survey of North American producers found poor uptake of socialisation in these systems (Ison et al., in press). It is worth noting that those who used the technique found it to be more useful than any other mitigation strategy (Ison et al., in press).

\subsection{Pheromones}

PAP diffusers have been commercially available from at least one company since 2015 (Semiokeys, 2018a); they advise that one diffuser covers an area of $25 \mathrm{~m}^{2}$ and should be replaced every six weeks. Importantly, the Semiokeys website provides a calculator allowing customers to track behavioural changes in their treated pens, compare performance to untreated controls, and to assess the economic impact of using pheromones on their own farms (SemioKeys, 2018b). Furthermore, several articles were written in French magazines and newsletters promoting the product. These mainly report the positive effects of the product, including: reductions in the number of fights, the duration of fights, cortisol, lesions, and tail biting (Huet, 2016; Semiokeys, 2016, 2017).

The majority of published research into PAP applied the pheromone in either liquid or aerosol form directly to the pens and feeders, and did not employ the commercially available diffusers. The only published research investigating the effectiveness of diffusers found limited efficacy (Plush et al., 2016). Research into PAP is ongoing and it is recommended that priority is given to determining the optimal application protocol under commercial conditions.

\section{The gap between research and practice}

Farmer willingness to change current practice and implement strategies to reduce aggression relies strongly on their perception of the situation. Pig farmers self-report having high regard for animal welfare (Wilson et al., 2014). However, they are faced with a myriad of often competing welfare problems such as tail biting; lameness; pain caused by routine husbandry procedures such as ear tagging and tail docking (Wilson et al., 2014); and heat stress (Pearce et al., 2013). Welfare may also compete with profit margins, food safety, product quality and environmental regulations (Millman et al., 2004). Therefore several factors compete for farmer attention, and it is possible that the costs associated with aggression are perceived as minor in comparison to those incurred by other threats to welfare and production. In a recent survey in the UK, $73 \%$ of 167 farmers did not regard aggression at weaning as a problem that needed to be addressed, compared to $57 \%$ at the growing-finishing stage (Camerlink and Turner, 2017). The farmers who perceived aggression as a problem displayed variable willingness to change the situation (Camerlink and Turner, 2017). This variation in response probably reflects the fact that human behaviour is determined by a wide range of intrinsic and extrinsic factors such as culture, social norms, education, awareness of legislation, attitudes, age and gender. Such factors were influential in determining antibiotic use, and campaigns that understood and addressed them managed to change human behaviour in both medical and agricultural/veterinary practice (Sabuncu et al., 2009; Huttner et al., 2010; Aarestrup, 2012).
Characteristics of the aggression mitigation strategy are also important. Reluctance to implement welfare improvement strategies is associated with the perception that they are ineffective, not financially feasible, or difficult to practically manage (Fredriksen and Nafstad, 2006). Motivation is limited when farmers distrust the economic advantages of implementing strategies or when the benefits are simply unknown (Bock and van Huik, 2007; Gocsik et al., 2015). Motivation is also reduced by a perceived lack of time, skilled labour (Morgan-Davies et al., 2006), or knowledge (de Lauwere et al., 2012). Commercial pig farmers have little choice but to farm animals in a way that will retain their competitive position in the market (Webster, 1982), and pig farmers are motivated markedly by economic factors (Bock and van Huik, 2007). Farmers are willing to adopt higher animal welfare standards as long as they fit the current farm set-up, are reversible and cover the additional costs (Gocsik et al., 2015). The lack of insight into the economic costs of aggression is likely to limit farmers' willingness to put resources into controlling the problem. There is a need for costeffectiveness analysis of aggression mitigation strategies to identify the most economically feasible approaches. This should complement efforts to quantify farmers' willingness to pay for welfare improvements that take the different capital and labour costs of implementing strategies into account.

Effective communication between researchers and farmers is vital at all stages of the research process for the successful development, acceptance, and adoption of innovations or techniques (Clarke, 2003). It is acknowledged that, although communication of science is important, it is generally not done well (Treise and Weigold, 2002) and requires improvement (Clarke, 2003; Grandin, 2003). It was previously recognised that there is a need for one-to-one communication and discussion, and for a move away from the unidirectional lecture format that both intimidates farmers and denies scientists the opportunity to respond based on the knowledge base of their audience (Clarke, 2003; Benard and Buning, 2013). For innovations to be implemented into industry they need to be well communicated and tested, and early adopters need to be supported to ensure successful implementation (Grandin, 2003). Who delivers the information may be important. Alarcon et al. (2014) found that veterinarians are a trusted source of information whilst researchers are associated with several negative themes, such as 'lack of communication', 'not knowing where to look', and 'information bias' (Alarcon et al., 2014). Therefore, the support of mitigation strategies by veterinarians may improve the practical application of research findings.

Societal concern about animal welfare has driven change in practice for several animal welfare issues, with campaigns to bring change either resulting in government regulations or change in retailer standards, for example in restricting use of conventional battery cages for laying hens (Appleby, 2003), sow stalls and veal crates for calves in the EU (Druce and Lymbery, 2006). A European Commission study found that $76 \%$ of EU citizens (from a sample of over 24,000) believe that they can influence the welfare of farmed animals for the better through their purchasing behaviour (European Commission, 2005). However, consumers have limited knowledge of intensive animal husbandry systems (Schröder and McEachern, 2004), and problems like pig aggression are unknown to the majority of society and therefore may not drive industry towards change on this matter.

\section{Conclusions and recommendations}

Mixing aggression between pigs continues to be an important topic in animal welfare research as the problem persists in practice. Although research has identified a number of aggression mitigation strategies they are not being implemented much at industry level. Apart from keeping pigs in stable groups throughout the production cycle there is no unified solution to effectively reduce aggression. Rather, aggression like many other welfare problems requires a multidisciplinary solution. Breeding and pre-weaning socialisation can help animals to better cope 
with the commercial farming environment. Housing pigs in relatively large groups, while providing a diet high in tryptophan, and providing synthetic maternal pheromones and sufficient space, may create an environment that reduces aggressive behaviour. There is minimal uptake of these mitigation strategies which may be due to low prioritisation of the problem, the practicalities of implementation, ineffective communication of research to the farming community and economic factors.

We recommend that researchers provide evidence that strategies are practical in a commercial farming environment; that they calculate the economic cost-effectiveness of doing so; and that they effectively communicate this information to farmers and other stakeholders. Where possible, farmers and other stakeholders should be involved in the early stages of a project so that they can contribute effectively to designing interventions. We recommend a better alignment between research questions and industry interests to increase the success of research efforts to improve animal welfare in practice.

\section{Conflicts of interest}

The authors declare to have no conflicts of interest.

\section{Acknowledgements}

This research was funded by Scotland's Rural College (SRUC). SRUC receives financial support from the Scottish Government. We would like to thank Professor Eddie Clutton for providing constructive comments on the manuscript.

\section{References}

Aarestrup, F., 2012. Get pigs off antibiotics. Nature 486, 465-466.

Adeola, O., Ball, R.O., 1992. Hypothalamic neurotransmitter concentration and meat quality in stressed pigs offered excess dietary tryptophan and tyrosine. J. Anim. Sci. $70,1888-1894$

Agriculture and Horticulture Development Board, 2016. The Current State of the UK Pig Market, Briefing Document.The Current State of the UK Pig Market, Briefing Document.

Alarcon, P., Wieland, B., Mateus, A.L.P., Dewberry, C., 2014. Pig farmers' perceptions, attitudes, influences and management of information in the decision-making process for disease control. Prev. Vet. Med. 116, 223-242.

Andersen, I.L., Andenaes, H., Boe, K.E., Jensen, P., Bakken, M., 2000. The effects of weight asymmetry and resource distribution on aggression in groups of unacquainted pigs. Appl. Anim.Behav. Sci. 68, 107-120.

Andersen, I.L., Naevdal, E., Bakken, M., Boe, K.E., 2004. Aggression and group size in domesticated pigs, Sus scrofa: 'when the winner takes it all and the loser is standing small'. Anim. Behav, 68, 965-975.

Appleby, M.C., 2003. European union ban on conventional cages for laying hens: history and prospects. J. Appl. Anim. Welf. Sci. 6, 103-121.

Arey, D.S., Edwards, S.A., 1998. Factors influencing aggression between sows after mixing and the consequences for welfare and production. Livestock Prod. Sci. 56, $61-70$.

Barnett, J.L., Cronin, G.M., McCallum, T.H., Newman, E.A., 1994. Effects of food and time of day on aggression when grouping unfamiliar pigs. App. Anim. Behav. Sci. 39, 339-347.

Benard, M., Buning, T.D., 2013. Exploring the potential of dutch pig farmers and urbancitizens to learn through frame reflection. J. Agric. Environ. Ethics 26, 1015-1036.

Bijma, P., 2014. The quantitative genetics of indirect genetic effects: a selective review of modelling issues. Heredity 112, 61-69.

Blackshaw, J.K., 1981. The effect of pen design and the tranquilizing drug, azaperone, on the growth and behaviour of weaned pigs. Aust. Vet. J. 57, 272-276.

Bock, B.B., van Huik, M.M., 2007. Animal welfare: the attitudes and behaviour of European pig farmers. Br. Food J. 109, 931-944.

Brummer, F., Moeller, S.J., Bernick, K., 2008. In: Gateway, P.I. (Ed.), Automatic Sorting Technology for Large Pen Finishing, . http://porkgateway.org.

Bulens, A., Van Beirendonck, S., Van Thielen, J., Buys, N., Driessen, B., 2017. Hiding walls for fattening pigs: do they affect behavior and performance? Appl. Anim. Behav. Sci. 195, 32-37.

Caine, W.R., Schaefer, A.L., Aalhus, J.L., Dugan, M.E.R., 2000. Behaviour, growth performance and pork quality of pigs differing in porcine stress syndrome genotype receiving dietary magnesium aspartate hydrochloride. Can. J. Anim. Sci. 80, $175-182$.

Camerlink, I., Turner, S.P., 2017. Farmers' perceptions of aggression between growing pigs. Appl. Anim. Behav. Sci. 192C, 42-47.

Camerlink, I., Bijma, P., Kemp, B., Bolhuis, J.E., 2012. Relationship between growth rate and oral manipulation, social nosing, and aggression in finishing pigs. Appl. Anim.
Behav. Sci. 142, 11-17

Camerlink, I., Turner, S.P., Bijma, P., Bolhuis, J.E., 2013. Indirect genetic effects and housing conditions in relation to aggressive behaviour in pigs. PLoS One 8, 9.

Canario, L., Turner, S.P., Roehe, R., Lundeheim, N., D'Eath, R.B., Lawrence, A.B., Knol, E., Bergsma, R., Rydhmer, L., 2012. Genetic associations between behavioral traits and direct-social effects of growth rate in pigs. J. Anim. Sci. 90, 4706-4715.

Clark, C.C.A., D'Eath, R.B., 2013. Age over experience: consistency of aggression and mounting behaviour in male and female pigs. Appl. Anim. Behav. Sci. 147, 81-93.

Clarke, B., 2003. Report: farmers and scientists - a case study in facilitating communication. Sci. Commun. 25, 198-203.

Coutellier, L., Arnould, C., Boissy, A., Orgeur, P., Prunier, A., Veissier, I., Meunier-Salaun, M.C., 2007. Pig's responses to repeated social regrouping and relocation during the growing-finishing period. Appl. Anim. Behav. Sci. 105, 102-114.

D'Eath, R.B., Ormandy, E., Lawrence, A.B., Sumner, B.E.H., Meddle, S.L., 2005. Residentintruder trait aggression is associated with differences in lysine vasopressin and serotonin receptor 1A (5-HT1A) mRNA expression in the brain of pre-pubertal female domestic pigs (Sus scrofa). J. Neuroendocrinol. 17, 679-686.

D'Eath, R.B., Turner, S.P., Kurt, E., Evans, G., Tholking, L., Looft, H., Wimmers, K., Murani, E., Klont, R., Foury, A., Ison, S.H., Lawrence, A.B., Mormede, P., 2010. Pigs' aggressive temperament affects pre-slaughter mixing aggression, stress and meat quality. Animal 4, 604-616.

D'Eath, R.B., 2005. Socialising piglets before weaning improves social hierarchy formation when pigs are mixed post-weaning. Appl. Anim. Behav. Sci. 93, 199-211.

Dapoza, C., 2009. Tryptophan in Swine Nutrition. https://www.pig333.com/nutrition/ tryptophan-in-swine-nutrition_2088/ (Accessed: 6th June 2017).

de Lauwere, C., van Asseldonk, M., van't Riet, J., de Hoop, J., ten Pierick, E., 2012. Understanding farmers' decisions with regard to animal welfare: the case of changing to group housing for pregnant sows. Livestock Sci. 143, 151-161.

Desire, S., Turner, S.P., D'Eath, R.B., Doeschl-Wilson, A.B., Lewis, C.R.G., Roehe, R., 2015a. Genetic associations of short- and long-term aggressiveness identified by skin lesion with growth, feed efficiency, and carcass characteristics in growing pigs. J. Anim. Sci. 93, 3303-3312.

Desire, S., Turner, S.P., D'Eath, R.B., Doeschl-Wilson, A.B., Lewis, C.R.G., Roehe, R., 2015b. Analysis of the phenotypic link between behavioural traits at mixing and increased long-term social stability. Appl. Anim. Behav. Sci. 52-62.

Druce, C., Lymbery, P., 2006. Outlawed in europe. In: Singer, P. (Ed.), Defense of Animals: The Second Wave. Blackwell Publishing Ltd.

Edwards, S.A., Mauchline, S., Stewart, A.H., 1993. Designing pens to minimize aggression when sows are mixed. Farm Build. Prog. 20-23.

Ellen, E.D., Rodenburg, T.B., Albers, G.A.A., Bolhuis, J.E., Camerlink, I., Duijvesteijn, N., Knol, E.F., Muir, W.M., Peeters, K., Reimert, I., Sell-Kubiak, E., van Arendonk, J.A.M., Visscher, J., Bijma, P., 2014. The prospects of selection for social genetic effects to improve welfare and productivity in livestock. Front. Genet. 5.

EU Council Directive 2008/120/EC, 2008. EU Council Directive 2008/120/EC of 18 December 2008 Laying Down Minimum Standards for the Protection of Pigs (Codified version). Available at: < http://eur-lex.europa.eu/LexUriServ/LexUriServ.do?uri = CELEX:32008L0120:en:NOT >

European Commision, 2005. Special Eurobarometer 229, Attitudes of Consumers Towards the Welfare of Farmed Animals. (Brussels).

Francis, D.A., Christison, G.I., Cymbaluk, N.F., 1996. Uniform or heterogeneous weight groups as factors in mixing weanling pigs. Can. J. Anim. Sci. 76, 171-176.

Fredriksen, B., Nafstad, O., 2006. Surveyed attitudes, perceptions and practices in Norway regarding the use of local anaesthesia in piglet castration. Res. Vet. Sci. 81, 293-295.

Fredriksen, B., Lium, B.M., Marka, C.H., Mosveen, B., Nafstad, O., 2008. Entire male pigs in farrow-to-finish pens - effects on animal welfare. Appl. Anim. Behav. Sci. 110, $258-268$.

Gabor, T.M., Hellgren, E.C., Van den Bussche, R.A., Silvy, N.J., 1999. Demography, sociospatial behaviour and genetics of feral pigs (Sus scrofa) in a semi-arid environment. J. Zool. 247, 311-322.

Gadd, J., 2009. Some Thoughts on Big Pens. www.pigprogress.net.

Gocsik, E., van der Lans, I.A., Lansink, A., Saatkamp, H.W., 2015. Willingness of Dutch broiler and pig farmers to convert to production systems with improved welfare. Anim. Welfare 24, 211-222.

Gonyou, H.W., Parfet, K.A.R., Anderson, D.B., Olson, R.D., 1988. Effects of amperozide and azaperone on aggression and productivity of growing-finishing pigs. J. Anim. Sci. 66, 2856-2864.

Gonyou, H.W., 2001. The social behaviour of pigs. In: Keeling, L.J., Gonyou, H.W. (Eds.), Social Behaviour in Farm Animals. CAB International, Wallingford, UK, pp. 147-176.

Grandin, T., Bruning, J., 1992. Boar presence reduces fighting in mixed slaughter-weight pigs. Appl. Anim. Behav. Sci. 33, 273-276.

Grandin, T., 2003. Transferring results of behavioral research to industry to improve animal welfare on the farm, ranch and the slaughter plant. Appl. Anim. Behav. Sci. 81, 215-228.

Greenwood, E.C., Plush, K.J., van Wettere, W., Hughes, P.E., 2014. Hierarchy formation in newly mixed, group housed sows and management strategies aimed at reducing its impact. Appl. Anim. Behav. Sci. 160, 1-11.

Guy, J.H., Bums, S.E., Barker, J.M., Edwards, S.A., 2009. Reducing post-mixing aggression and skin lesions in weaned pigs by application of a synthetic maternal pheromone. Anim. Welfare 18, 249-255.

Guzik, A.C., Matthews, J.O., Kerr, B.J., Bidner, T.D., Southern, L.L., 2006. Dietary tryptophan effects on plasma and salivary cortisol and meat quality in pigs. J. Anim. Sci. 84, 2251-2259.

Hemsworth, P.H., Rice, M., Nash, J., Giri, K., Butler, K.L., Tilbrook, A.J., Morrison, R.S., 2013. Effects of group size and floor space allowance on grouped sows: aggression, stress, skin injuries, and reproductive performance. J. Anim. Sci. 91, 4953-4964. 
Hessel, E.F., Reiners, K., Van den Weghe, H.F.A., 2006. Socializing piglets before weaning: effects on behavior of lactating sows, pre- and postweaning behavior, and performance of piglets. J. Anim. Sci. 84, 2847-2855.

Huet, S., 2016. Moins de stress avec les phéromones maternelles [Less stress with maternal pheromones]. L'avenir agricole 1779, 14.

Huttner, B., Goossens, H., Verheij, T., Harbarth, S., Consortium, C., 2010. Characteristics and outcomes of public campaigns aimed at improving the use of antibiotics in outpatients in high-income countries. Lancet Infect. Dis. 10, 17-31.

Ismayilova, G., Sonoda, L., Fels, M., Rizzi, R., Oczak, M., Viazzi, S., Vranken, E., Hartung, J., Berckmans, D., Guarino, M., 2014. Acoustic-reward learning as a method to reduce the incidence of aggressive and abnormal behaviours among newly mixed piglets. Anim. Produc. Sci. 54, 1084-1090.

Ison, S.H., Bates, R.O., Ernst, C.W., Steibel, J.P., Siegford, J.M., 2018. Housing, ease of handling and minimizing inter-pig aggression at mixing for nursery to finisher pigs as reported in a survey to North American pork producers. Appl. Anim. Behav. Sci SI: Understanding Animal Behaviour (in press).

Jensen, P., Wood-Gush, D.G.M., 1984. Social interactions in a group of free-ranging sows. Appl. Anim. Behav. Sci. 12, 327-337.

Jensen, P., Yngvesson, J., 1998. Aggression between unacquainted pigs - sequential as sessment and effects of familiarity and weight. Appl. Anim. Behav. Sci. 58, 49-61.

Kanaan, V.T., Pajor, E.A., Lay, D.C., Richert, B.T., Garner, J.P., 2008. A note on the effects of co-mingling piglet litters on pre-weaning growth, injuries and responses to behavioural tests. Appl. Anim. Behav. Sci. 110, 386-391.

Koopmans, S.J., Ruis, M., Dekker, R., van Diepen, H., Korte, M., Mroz, Z., 2005. Surplus dietary tryptophan reduces plasma cortisol and noradrenaline concentrations and enhances recovery after social stress in pigs. Physiol. Behav. 85, 469-478.

Koopmans, S.J., Guzik, A.C., van der Meulen, J., Dekker, R., Kogut, J., Kerr, B.J., Southern, L.L., 2006. Effects of supplemental L-tryptophan on serotonin, cortisol, intestinal integrity, and behavior in weanling piglets. J. Anim. Sci. 84, 963-971.

Kutzer, T., Bunger, B., Kjaer, J.B., Schrader, L., 2009. Effects of early contact between non-littermate piglets and of the complexity of farrowing conditions on social behaviour and weight gain. Appl. Anim. Behav. Sci. 121, 16-24.

Ledergerber, K., Bennett, B., Diefenbacher, N., Shilling, C., Whitaker, B.D., 2015. The effects of socializing and environmental enrichments on sow and piglet behavior and performance. Ohio J. Sci. 115, 40-47.

Li, Y.Z., Kerr, B.J., Kidd, K.T., Gonyou, H.W., 2006. Use of supplementary tryptophan to modify the behavior of pigs. J. Anim. Sci. 84, 212-220.

Li, Y.Z., Baidoo, S.K., Johnston, L.J., Anderson, J.E., 2011. Effects of tryptophan supplementation on aggression among group-housed gestating sows. J. Anim. Sci. 89, 1899-1907.

Lovendahl, P., Damgaard, L.H., Nielsen, B.L., Thodberg, K., Su, G.S., Rydhmer, L., 2005. Aggressive behaviour of sows at mixing and maternal behaviour are heritable and genetically correlated traits. Livestock Prod. Sci. 93, 73-85.

Maletinska, J., Špinka, M., 2001. Cross-suckling and nursing synchronisation in group housed lactating sows. Appl. Anim. Behav. Sci. 75, 17-32.

Manteca, X., Jones, B., 2013. Welfare Improvement Strategies Improving Farm Animal Welfare: Science and Society Working Together: The Welfare Quality Approach. pp. 175-200.

Marchant-Forde, J.N., Marchant-Forde, R.M., 2005. Minimizing inter-pig aggression during mixing. Pig News Inf. 26 (3) 63N.

McGlone, J.J., Anderson, D.L., 2002. Synthetic maternal pheromone stimulates feeding behavior and weight gain in weaned pigs. J. Anim. Sci. 80, 3179-3183.

McGlone, J.J., Curtis, S.E., 1985. Behaviour and performance of weanling pigs in pens equipped with hide areas. J. Anim. Sci. 60, 20-24.

McGlone, J.J., 1985. A quantitative ethogram of aggressive and submissive behaviours in recently regrouped pigs. J. Anim. Sci. 61, 559-565.

Mendl, M., Zanella, A.J., Broom, D.M., 1992. Physiological and reproductive correlates of behavioural strategies in female domestic pigs. Anim. Behav. 44, 1107-1121.

Millman, S.T., Duncan, I.J.H., Stauffacher, M., Stookey, J.A., 2004. The impact of applied ethologists and the International Society for Applied Ethology in improving animal welfare. Appl. Anim. Behav. Sci. 86, 299-311.

Moore, A.J., Brodie, E.D., Wolf, J.B., 1997. Interacting phenotypes and the evolutionary process .1. Direct and indirect genetic effects of social interactions. Evolution 51 1352-1362.

Morgan-Davies, C., Waterhouse, A., Milne, C.E., Stott, A.W., 2006. Farmers' opinions on welfare, health and production practices in extensive hill sheep flocks in Great Britain. Livestock Sci. 104, 268-277.

Morrow-Tesch, J.L., McGlone, J.J., 1990. Sources of maternal odors and the development of odor preferences in baby pigs. J. Anim. Sci. 68, 3563-3571.

Morrow-Tesch, J.L., McGlone, J.J., Salakjohnson, J.L., 1994. Heat and social stress effects on pig immune measures. J. Anim. Sci. 72, 2599-2609.

National Hog Farmer, 2010. Amino Acid Supplement Reduces Aggression in Young Female Pigs. http://www.nationalhogfarmer.com/nutrition/ingredients/amino-acidreduces-aggression-0319 (Accessed: 26th June 2017).

O'Driscoll, K., O'Gorman, D.M., Taylor, S., Boyle, L.A., 2013a. The influence of a magnesium-rich marine extract on behaviour, salivary cortisol levels and skin lesions in growing pigs. Animal 7, 1017-1027.

O'Driscoll, K., Teixeira, D.L., O'Gorman, D., Taylor, S., Boyle, L.A., 2013b. The influence of a magnesium rich marine supplement on behaviour, salivary cortisol levels, and skin lesions in growing pigs exposed to acute stressors. Appl. Anim. Behav. Sci. 145, 92-101.

Olesen, L.S., Nygaard, C.M., Friend, T.H., Bushong, D., Knabe, D.A., Vestergaard, K.S., Vaughan, R.K., 1996. Effect of partitioning pens on aggressive behavior of pigs regrouped at weaning. Appl. Anim. Behav. Sci. 46, 167-174.

Olsen, A.N.W., Dybkjaer, L., Vestergaard, K.S., 1998. Cross-suckling and associated behaviour in piglets and sows. Appl. Anim. Behav. Sci. 61, 13-24.
Pageat, P., 2001. Pig Appeasing Pheromones to Decrease Stress, Anxiety and Aggressiveness US.Pig Appeasing Pheromones to Decrease Stress, Anxiety and Aggressiveness US.

Pandolfi, F., Kyriazakis, I., Stoddart, K., Wainwright, N., Edwards, S.A., 2017. The Real Welfare scheme: identification of risk and protective factors for welfare outcomes in commercial pig farms in the UK. Prev. Vet. Med. 146, 34-43.

Parratt, C.A., Chapman, K.J., Turner, C., Jones, P.H., Mendl, M.T., Miller, B.G., 2006. The fighting behaviour of piglets mixed before and after weaning in the presence or absence of a sow. Appl. Anim. Behav. Sci. 101, 54-67.

Pearce, S.C., Gabler, N.K., Ross, J.W., Escobar, J., Patience, J.F., Rhoads, R.P., Baumgard, L.H., 2013. The effects of heat stress and plane of nutrition on metabolism in growing pigs. J. Anim. Sci. 91, 2108-2118.

Peden, R.S.E., Turner, S.P., Camerlink, I., 2018. Unpublished Work. PhD Project: Demand Driven Solutions to Reduce Aggression Between Pigs. Scotland's Rural College.

Pedersen, L.J., Studnitz, M., Jensen, K.H., Giersing, A.M., 1998. Suckling behaviour of piglets in relation to accessibility to the sow and the presence of foreign litters. Appl. Anim. Behav. Sci. 58, 267-279.

Petherick, J.C., Blackshaw, J.K., 1987. A review of the factors influencing the aggressive and agonistic behaviour of the domestic pig. Aust. J. Exp. Agric. 27, 605-611.

Phys.Org, 2010. Tryptophan-enriched Diet Reduces Pig Aggression. https://phys.org/ news/2010-03-tryptophan-enriched-diet-pig-aggression.html [Accessed: 16 June 2017].

Plush, K., Hughes, P., Herde, P., van Wettere, W., 2016. A synthetic olfactory agonist reduces aggression when sows are mixed into small groups. Appl. Anim. Behav. Sci. 185, 45-51.

Poletto, R., Meisel, R.L., Richert, B.T., Cheng, H.W., Marchant-Forde, J.N., 2010. Aggression in replacement grower and finisher gilts fed a short-term high-tryptophan diet and the effect of long-term human-animal interaction. Appl. Anim. Behav. Sci. $122,98-110$.

Poletto, R., Kretzer, F.C., Hotzel, M.J., 2014. Minimizing aggression during mixing of gestating sows with supplementation of a tryptophan-enriched diet. Physiol. Behav. 132, 36-43.

Rauterberg, S., Sonoda, L.T., Fels, M., Viazzi, S., Ismayilova, G., Oczak, M., Bahr, C., Guarino, M., Vranken, E., Berckmans, D., Hartung, J., 2013. Cognitive enrichment in the farrowing pen - a first approach to use early behavioural conditioning of suckling piglets to reduce aggressive behaviour during rearing. Zuchtungskunde 85, 376-387.

Real Welfare, 2017. Baseline report: 2013-2016. Measuring welfare outcomes in pigs. Agric. Hortic. Dev. Board 1-20.

Rushen, J., 1987. A difference in weight reduces fighting when unaquainted newly weaned pigs 1 st meet Canadian. J. Anim. Sci. 67, 951-960.

Rydhmer, L., Zamaratskaia, G., Andersson, H.K., Algers, B., Guillemet, R., Lundstrom, K. 2006. Aggressive and sexual behaviour of growing and finishing pigs reared in groups, without castration. Acta Agric. Scand. Section a-Anim. Sci. 56, 109-119.

Sabuncu, E., David, J., Bernede-Bauduin, C., Pepin, S., Leroy, M., Boelle, P.Y., Watier, L., Guillemot, D., 2009. Significant reduction of antibiotic use in the community after a nationwide campaign in France, 2002-2007. PLoS Med. 6.

Salvage, B., 2010. Pig Aggression Cut by Tryptophan Enriched Diet, Meat Poultry; https://www.meatpoultry.com/articles/news_home/Business/2010/03/Pig_aggression_cut_by_tryptoph.aspx?ID = \{0DAD4970-777C-4981-9250-8797E21059FD $\}$ \& cck $=1$ (Accessed: 16th June 2017).

Samarakone, T.S., Gonyou, H.W., 2009. Domestic pigs alter their social strategy in response to social group size. Appl. Anim. Behav. Sci. 121, 8-15.

Schröder, M.J.A., McEachern, M.G., 2004. Consumer value conflicts surrounding ethical food purchase decisions: a focus on animal welfare. Int. J. Consum. Stud. 28, 168-177.

Seguin, M.J., Friendship, R.M., Kirkwood, R.N., Zanella, A.J., Widowski, T.M., 2006. Effects of boar presence on agonistic behavior, shoulder scratches, and stress response of bred sows at mixing. J. Anim. Sci. 84, 1227-1237.

Semiokeys, 2016. Limite le stress chez le porc [Limit stress in pigs]. Réussir. Porc. 240, 36

Semiokeys, 2017. Des pheromones pour des cochons zen [Pheromones for zen pigs]. Porcmag 516, 38-39.

Semiokeys, 2018a. SecurePig. https://www.semiokeys.com/en/ (Accessed: 28th June 2017).

SemioKeys, 2018b. SemioKeys Calculator. https://matrice.semiokeys.com/ (Accessed: 28th June 2017).

Shen, Y.B., Voilque, G., Odle, J., Kim, S.W., 2012b. Dietary L-Tryptophan supplementation with reduced large neutral amino acids enhances feed efficiency and decreases stress hormone secretion in nursery pigs under social-mixing stress. J. Nutr. 142, 1540-1546.

Shen, Y.B., Voilque, G., Kim, J.D., Odle, J., Kim, S.W., 2012a. Effects of increasing tryptophan intake on growth and physiological changes in nursery pigs. J. Anim. Sci. 90, 2264-2275.

Sonoda, L., Fels, M., Rauterberg, S., Viazzi, S., Ismayilova, G., Oczak, M., Bahr, C., Guarino, M., Vranken, E., Berckmans, D., Hartung, J., 2013. Cognitive enrichment in piglet rearing: an approach to enhance animal welfare and to reduce aggressive behaviour. ISRN Vet. Sci. 2013, 1-9.

Spoolder, H.A.M., Geudeke, M.J., Van der Peet-Schwering, C.M.C., Soede, N.M., 2009 Group housing of sows in early pregnancy: a review of success and risk factors. Livestock Sci. 125, 1-14.

Stolba, A., Wood-Gush, D.G.M., 1989. The behviour of pigs in a semi-natural environment. Anim. Prod. 48, 419-425.

Stookey, J.M., Gonyou, H.W., 1994. The effects of regrouping on behavioural and production parameters in finishing swine. J. Anim. Sci. 72, 2804-2811.

Tan, S.S.L., Shackleton, D.M., 1990. Effexts of mixing unfamiliar individuals and of azaperone on the social-behaviour of finishing pigs. Appl. Anim. Behav. Sci. 26, 157-168. 
ter Beek, V., 2010. Tryptophan Eases Aggression in Pigs, Pig World. http://www. pigprogress.net/Home/General/2010/1/Tryptophan-eases-aggression-in-pigsPP003811W/ Accessed: 11th May 2017).

Terlouw, E.M.C., Arnould, C., Auperin, B., Berri, C., Le Bihan-Duval, E., Deiss, V., Lefevre, F., Lensink, B.J., Mounier, L., 2008. Pre-slaughter conditions, animal stress and welfare: current status and possible future research. Animal 2, 1501-1517.

Treise, D., Weigold, M.F., 2002. Advancing science communication - A survey of science communicators. Sci. Commun. 23, 310-322.

Turner, S.P., Ewen, M., Rooke, J.A., Edwards, S.A., 2000. The effect of space allowance on performance, aggression and immune competence of growing pigs housed on straw deep-litter at different group sizes. Livestock Prod. Sci. 66, 47-55.

Turner, S.P., Horgan, G.W., Edwards, S.A., 2001. Effect of social group size on aggressive behaviour between unacquainted domestic pigs. Appl. Anim. Behav. Sci. 74 203-215.

Turner, S.P., Horgan, G.W., Edwards, S.A., 2003. Assessment of sub-grouping behaviour in pigs housed at different group sizes. Appl. Anim. Behav. Sci. 83, 291-302.

Turner, S.P., Farnworth, M.J., White, I.M.S., Brotherstone, S., Mendl, M., Knap, P., Penny, P., Lawrence, A.B., 2006a. The accumulation of skin lesions and their use as a predictor of individual aggressiveness in pigs. Appl. Anim. Behav. Sci. 96, 245-259.

Turner, S.P., White, I.M.S., Brotherstone, S., Farnworth, M.J., Knap, P.W., Penny, P., Mendl, M., Lawrence, A.B., 2006b. Heritability of post-mixing aggressiveness in grower-stage pigs and its relationship with production traits. Anim. Sci. 82, 615-620.

Turner, S.P., Roehe, R., Mekkawy, W., Farnworth, M.J., Knap, P.W., Lawrence, A.B., 2008. Bayesian analysis of genetic associations of skin lesions and behavioural traits to identify genetic components of individual aggressiveness in pigs. Behav. Genet. 38, $67-75$.

Turner, S.P., Roehe, R., D'Eath, R.B., Ison, S.H., Farish, M., Jack, M.C., Lundeheim, N., Rydhmer, L., Lawrence, A.B., 2009. Genetic validation of postmixing skin injuries in pigs as an indicator of aggressiveness and the relationship with injuries under more stable social conditions. J. Anim. Sci. 87, 3076-3082.
Turner, S.P., D'Eath, R.B., Roehe, R., Lawrence, A.B., 2010. Selection against aggressiveness in pigs at re-grouping: practical application and implications for long-term behavioural patterns. Anim. Welfare 19, 123-132.

van Nieuwamerongen, S.E., Soede, N.M., van der Peet-Schwering, C.M.C., Kemp, B., Bolhuis, J.E., 2015. Development of piglets raised in a new multi-litter housing system vs. conventional single-litter housing until 9 weeks of age. J. Anim. Sci. 93, 5442-5454.

Wattanakul, W., Sinclair, A.G., Stewart, A.H., Edwards, S.A., English, P.R., 1997a Performance and behaviour of lactating sows and piglets in crate and multisuckling systems: a study involving European White and Manor Meishan genotypes. Anim. Sci. 64, 339-349.

Wattanakul, W., Stewart, A.H., Edwards, S.A., English, P.R., 1997b. Effects of grouping piglets and changing sow location on suckling behaviour and performance. Appl. Anim. Behav. Sci. 55, 21-35.

Weary, D.M., Pajor, E.A., Bonenfant, M., Ross, S.K., Fraser, D., Kramer, D.L., 1999. Alternative housing for sows and litters: 2: effects of a communal piglet area on preand post-weaning behaviour and performance. Appl. Anim. Behav. Sci. 65, 123-135.

Webster, A.J.F., 1982. The economics of farm animal-welfare. Int. J. Stud. Anim. Problems 3, 301-306.

Wilson, R.L., Holyoake, P.K., Cronin, G.M., Doyle, R.E., 2014. Managing animal wellbeing: a preliminary survey of pig farmers. Aust. Vet. J. 92, 206-212.

Yonezawa, T., Koori, M., Kikusui, T., Mori, Y., 2009. Appeasing pheromone inhibits cortisol augmentation and agonistic behaviors during social stress in adult miniature pigs. Zoolog. Sci. 26, 739-744.

Ziggers, D., 2009. Tryptophan Eases Aggression in Pigs, All About Feed. http://www. allaboutfeed.net/Home/General/2009/12/Tryptophan-eases-aggression-in-pigsAAF003963W/ (Accessed: 16th June 2017).

Ziggers, D., 2010. Tryptophan Reduces Aggressiveness in Pigs, All About Feed. http:// www.allaboutfeed.net/Home/General/2010/3/Tryptophan-reduces-aggressivenessin-pigs-AAF004261W/ (Accessed: 16th June 2017). 